\title{
The Level of Compliance of Food Handlers with National Regulations on Food Hygiene and Safety Practices: A Case of Selected Fast Food Outlets in Thohoyandou, South Africa
}

\author{
T.S Murwira ${ }^{1, *}$, A.M Amosu ${ }^{2}$, L.H Nemathaga ${ }^{1}$ \\ ${ }^{1}$ Department of Public Health, University of Venda, Republic of South Africa \\ ${ }^{2}$ Department of Nursing Science, University of Venda, Republic of South Africa
}

Copyright $(2017$ by authors, all rights reserved. Authors agree that this article remains permanently open access under the terms of the Creative Commons Attribution License 4.0 International License

\begin{abstract}
Food safety is becoming a key public health priority because a large number of people consume their meals outside their homes. As a result, they are exposed to food borne illnesses that originate from food stalls, restaurants and other food outlets. Hence the study focused on level of compliance of food handlers with national regulations on food hygiene and safety practices. The method used to collect data was participant observational checklist where the researcher had to go round with the workers during their daily chores. Simple random sampling was used to select 122 food handlers as participants in the study. Fast food outlets were also evaluated according to codified regulations and sixty food premises were observed for compliance using a checklist and compared with standards and the requirements prescribed by in Foodstuffs, Cosmetics and Disinfectants Act of 1972, regulation Data analysis involved descriptive statistics (frequencies and percentages) and analysis was made based on the standards and the requirements prescribed by Regulation R962 of November 2012. The findings showed that food handlers observed personal hygiene by wearing clean uniforms, covering their heads with hair nets, and washed their hands, indicating that food handlers maintained accepted standards in terms of personal hygiene regulations.
\end{abstract}

Keywords Assessment, Food Handlers, Personal Hygiene, Fast Food Outlets

\section{Introduction}

Food borne disease outbreak of is common everywhere in developing countries including South Africa and fast food outlets are no exception. Outbreak of food borne outbreaks is a major challenge facing most urban municipalities in South Africa and Thulamela Municipality has a mammoth task to ensure that requirements of food hygiene regulatory compliance are met. Although there is no reliable statistics to show the magnitude of food borne diseases in South Africa there are outbreaks of food borne diseases which are mainly covered sporadically by the media. Regulatory compliance refers to obedience by a target population with regulations. For the people to obey any rule, several conditions are needed. Adherence to food safety regulation has been associated with less food outbreaks hence reducing food borne diseases (Griffith 2000). In food health management enforcing the laws is the first line management strategy to prevent food borne which continue to undermine quality of life in developing countries.

\subsection{Literature Review}

World Health Organisation defines food safety as the conditions and measures that are necessary during production, processing, storage, distribution and preparation of food to ensure that it is safe, sound, and wholesome and fit for human consumption (WHO, 1984). Food safety remains a critical issue among professionals in the food service sector as well as consumers (Griffith, 2000). Food contamination may occur at any point during its journey through production, processing, distribution, and preparation (Green, et al., 2005). The risk of food getting contaminated depends largely on the health status of the food handlers, their personal hygiene, knowledge and practice of food hygiene. Griffith (2000) reported that, at the time, up to $70 \%$ of food-borne illness outbreaks in the UK were associated with food service functions such as restaurants, hotels, institutions and caterers. A common denominator in these sectors of the food chain (often collectively referred to as the food service sector), is 
the reliance on many manual processes resulting in large numbers of food handlers (Griffith 2000).

South Africa as a country is challenged by the outbreak of food borne diseases. Millions of South Africans contract food poisoning every year. The National Department of Health published South African statistics relating to food poisoning in 2006. The report looks at the number of reported food borne illnesses and fatalities between 2001 and 2005. A total number of 51 food borne illness related deaths were reported to the National Department of Health. It is noteworthy that many cases of food borne illness go unreported or are misdiagnosed or undiagnosed. Most of the cases reported were from the Eastern Cape followed by KwaZulu-Natal and Limpopo province (National Institute for Communicable Diseases, 2014).

Recently, in the Limpopo province of South Africa there have been 44 cases of diarrheal disease all linked to the attendance of an event at a lodge. Patients reported at the local hospital with diarrhoea and vomiting within 48 hours of first checking in on 20 January 2014 into the lodge and enjoying several meals. The first case was presented on 22 January 2014. A non-typhoid Salmonella species was confirmed by laboratory tests on stool specimens from the patients. The outbreak was investigated and preliminary reports pointed to a food borne illness directly related to food consumed by attendees of the event at the lodge (National Institute for Communicable Diseases, 2014).

Millions of people in South Africa eat out every day, utilising the food service sector. Although the lack of an effective reporting system makes it difficult to know how many of these people suffer from food-borne illness, statistics from the developed countries show that this number may be significant. The republic of South Africa government has developed a wide range of policies, acts, regulations and guidelines which aim at promoting and safeguarding public health in the fast food industry. However we are seeing variations, relaxations and disparities in their compliance. This results in jeopardizing the health of their customer. The situation is evidenced by the observations that we are witnessing the seasonal outbreaks of food borne diseases outbreaks around the country. In South Africa providing safe food to consumers is the responsibility of the food service provider. There is an added obligation on authorities to ensure that any establishment serving food to the general public does so in a manner that complies with the regulations, and to monitor compliance. These regulations are detailed in the Health Act, No. 63 of 1977 and the Foodstuffs, Cosmetics and Disinfectants Act of 1972. Furthermore, standards have been developed to guide food service establishments in providing safe food for human consumption. Previous studies have shown that regulatory compliance can improve adherence of food handlers to personal hygiene and food safety practices (Griffith 2000). In South Africa, the food handlers have to adhere to a number of health regulations and guidelines which are updated with international standards from Code Alimentarius regulations on food hygiene.
To ensure effective food control, it is crucial that the catering industry control regulatory activities that are enforced by health authorities or local authorities so as to provide consumers with the necessary protection. This requires a safety and sanitation system that will consistently provide the certainty that food is prepared and served under safe and sanitary conditions. This demands the compliance to standard hygiene requirements specified in the regulation to prevent the outbreak of food borne illnesses. This entails the implementation of a food system such as hazard analysis critical control point (HACCP) that prevents problems before they occur. Health regulations were developed for people who prepare food for public. Compliance to the health regulations stipulated by Food, Cosmetic and Disinfectant Act of 1972 will ensure that food prepared for human consumption is safe and healthy.

Regulatory compliance ensures that innocent lives are saved and unnecessary deaths are prevented. Since health and safety is a global issue of concern, and in order to safeguard customers health against the risk of food poisoning arising from unhygienic preparation conditions, especially at public eating places like hotels and restaurants, certain health and safety laws are put in place by governments to regulate hotel and restaurant business operations (WHO, 2007). The purpose of the law is to regulate human activities (Schmalleger, 2006; and Aibor and Olorunda, 2006) in order to ensure that human and other forms of existence are not jeopardized in any way which includes health and safety. Even though laws are meant to be obeyed, certain degree of enforcement is necessary to serve as a measure of control.

\section{Methodology}

\subsection{Design}

A cross-sectional descriptive survey design that employed a quantitative paradigm was used in this study. This approach was suitable in the sense that it allowed variables to be quantified whilst at the same time facilitating descriptive analysis (Burns \& Grove, 2009; Polit \& Hungler, 2006).

\subsection{Study Setting}

Thohoyandou is a town in the Limpopo Province of South Africa. It is the administrative centre of Vhembe District Municipality and Thulamela Local Municipality. Thohoyandou is situated in the south of Vhembe district, on the main road between Louis Trichardt and the Kruger National Park. This is the lush agricultural centre of Vhembe, with banana plantations, subtropical fruit, and tobacco and maize lands. Thohoyandou is the second largest town in Venda after Makhado (Louis Trichardt), situated $79 \mathrm{~km}$ from Makhado and $53 \mathrm{~km}$ from Dzanani. The fast food outlets are situated in Thohoyandou central and its surrounding townships such as Shayandima and Sibasa. 


\subsection{Population}

The target population of this study involved all food handlers employed in licensed fast food outlets in Thohoyandou in Thulamela Municipality. There were about 178 food handlers registered as fast food outlets within the data base of Vhembe District Municipality database. The fast food outlets were categorised according to type of service they offer such as franchised operators, general food establishments and restaurants. The food handlers in the fast food outlets ranged from cooks, waiters and members of production staff.

\subsection{Sampling}

Based on the sampling frame of 178 , sample size of $n=122$ was calculated using Slovin's formula [n=N/ $\{1+\mathrm{Ne} 2\}]$ where $\mathrm{n}$ and $\mathrm{N}$ denote the sample and population sizes respectively with $\mathrm{e}=0.05$ as the margin of error (Guilford \& Frucher, 1973).The study used random sampling method. Probability or random sampling refers to "the selection of a sample in such a way that every individual in the accessible population has an equal chance of being selected for the study. Random sampling is done from a list of all the members of the population" (Brink et al., 2006). The first stage of the sampling process involved the selection of fast food outlets and all 60 fast food outlets were included in the study. Secondly, out of total population 178 food handlers a simple random technique was used to select participants from each fast food outlets to make a total of 122 participants. This process ensured that each participant had an equal chance of being selected, thus eliminating selection bias (Burns \& Grove, 2009). The sample comprised of 38(31\%) were males and $84(69 \%)$ were females.

\subsection{Data Collection}

A pre tested observation checklist was used to collect data. The observation checklist comprised of four sections. Section A was concerned by socio - demographic characteristics of food handlers;

Section B focused on personal hygiene practices, Section C: dwelt on health surveillance practices and Section D on pertained to hygiene infrastructure. The instrument was administered by a team comprising of the researcher and environmental health officers. The study was conducted over a two month period. The researchers were trained by the environmental health officers on how to carry out observations using the instrument and in turn the environmental health officers were trained to conduct research by the researcher. For each of the selected restaurants copies of instrument were completed by a team member who made direct observation and record the observation in the observation log immediately.

\subsection{Reliability and Validity Reliability}

Reliability was ensured by was ensured by conducting a pilot study. The respondents had similar characteristics to the study sample but did not form part of the actual study, to determine the clarity of items and consistency of the responses. Content validity was ensured by subjecting the instrument to senior lecturers and environmental health practioners.

\subsection{Ethical Considerations}

The nature and purpose of the study were explained to the respondents and management of the fast food outlets. Ethical approval was obtained from the University of Venda Research and Publication Committee. Approval to conduct the study was granted by Vhembe district municipality. Confidentiality, anonymity and privacy were assured to the respondents to maintain secrecy on names and personal information.

\subsection{Data Analysis}

The observations were coded and analysed using the Statistical Package for the Social Sciences (SPSS) version 21.0 software and Microsoft Excel. Being a purely descriptive study, descriptive statistics were used because they provide meaningful summaries about the sample and the variables (Trochim, 2006). Frequencies and percentages of responses to the questions were computed and represented using frequency distribution tables and graphs.

\section{Results}

The socio demographic characteristics of food handlers are shown in Table 1. One hundred and twenty two respondents participated in the study. Out of these, 38(31\%) were males and $84(69 \%)$ were females. Fifty eight (48\%) were between age $26-35,29(24 \%)$ were between ages 19-25 years and $35(29 \%)$ were 36 years and above. Twenty five $(20.5 \%)$ had primary education while $66(54.1 \%)$ had matriculated and 31(25.4) had tertiary qualification Forty $(33 \%)$ of the respondents attended food safety training regularly and $82(67 \%)$ did not attend training regularly.

Table 2 shows personal hygiene practices of the respondents. One hundred and fifteen 115(94\%) had their finger nails cut, $87(71 \%)$ washed hands with soap. Furthermore 118(98\%) were observed wearing clean uniforms while $122(100 \%)$ use aprons or hair nets to cover head.

In Table 3 other unhygienic behaviors spotted by the researchers. Only $2(1.6 \%)$ of the respondents were observed shaking hands whilst preparing food, whilst $1(0.8 \%)$ were found chewing whilst preparing food and 5(4\%) of respondents were observed collecting money at the same time serving or dishing food.

Figure 1 shows that $122(100 \%)$ respondents wore hairnets and apron respectively, while $25(20.5 \%)$ were observed wearing gloves when preparing food. Furthermore thirty three $(27 \%)$ were observed wearing work suits.

In Table 4 forty four (36\%) food handlers undergo regular medical checkup, 108(89\%) reported illness to their supervisors when sick, whilst 26(21.3\%) prepared food 
when suffering from cough. Furthermore 30(24.5\%) were observed with open sore on hands.

Table 1. Socio demographic characteristics of study sample $(\mathrm{N}=\mathbf{1 2 2})$

\begin{tabular}{|c|c|c|c|c|c|}
\hline \multirow{3}{*}{$\begin{array}{c}\text { Age } \\
\text { distribution } \\
\text { (years) }\end{array}$} & \multicolumn{4}{|c|}{ Sex distribution } & \multirow[t]{3}{*}{ total } \\
\hline & \multicolumn{2}{|c|}{ Male } & \multicolumn{2}{|c|}{ female } & \\
\hline & $\mathrm{N}$ & $\%$ & $\mathrm{~N}$ & $\%$ & \\
\hline $19-25$ & 12 & 9.8 & 17 & 13.9 & $29(24 \%)$ \\
\hline $26-35$ & 14 & 11.5 & 44 & 36 & $58(48 \%)$ \\
\hline$>36$ & 12 & 9.8 & 23 & 18.9 & $35(29 \%)$ \\
\hline Total & 38 & 31 & 84 & 69 & $122(100)$ \\
\hline \multicolumn{3}{|c|}{ Level of education } & \multicolumn{2}{|c|}{ No } & $\%$ \\
\hline \multicolumn{3}{|c|}{ Primary } & \multicolumn{2}{|c|}{25} & 20.5 \\
\hline \multicolumn{3}{|c|}{ Secondary } & \multicolumn{2}{|c|}{66} & 54.1 \\
\hline \multicolumn{3}{|c|}{ Tertiary } & \multicolumn{2}{|c|}{31} & 25.4 \\
\hline \multicolumn{6}{|c|}{ Food safety training attended } \\
\hline \multicolumn{3}{|c|}{ Yes } & \multicolumn{2}{|c|}{40} & 33 \\
\hline \multicolumn{3}{|c|}{ No } & \multicolumn{2}{|c|}{82} & 67 \\
\hline
\end{tabular}

In table 5 55(92\%) of fast food outlets are built in such a manner that the design and layout ensure good or proper hygiene, whilst 55 (92\%) protect against the accumulation of dirt. Concerning provision of water, $60(100 \%)$ of the facilities have potable running water whilst 59(98.3\%) allows for enough ventilation. Fifty five (92\%) of the facilities walls are free from dust, soot and spider web. Furthermore $49(82 \%)$ of the facilities are designed to prevent contamination of food, whilst $51(85 \%)$ floor are free from cracks. Forty $(66 \%)$ of premises do not have hot and cold water whilst $60(100 \%)$ had hand washing basins had soap and drying facilities. The observed environment around food premises showed that 55 (92\%) were clean and located a distance far from contaminating material such as waste water, toilet facilities, open drains and animals. Concerning the provision of soap, tissues and nail brushes in toilets, Fifty seven $(95 \%)$ of toilets observed had soap and comfortable to use $56(93 \%)$.

Table 2. Personal hygiene practices $(\mathbf{N}=\mathbf{1 2 2})$

\begin{tabular}{|c|c|c|}
\hline Personal hygiene practices & $\mathrm{N}=122$ & $\%$ \\
\hline Finger nails cut short & 115 & 94 \\
\hline Wash hands with soap & 87 & 71 \\
\hline $\begin{array}{c}\text { Wearing clean clothes while } \\
\text { working }\end{array}$ & 118 & 98 \\
\hline Wearing apron & 122 & 100 \\
\hline Hair covered & 122 & 100 \\
\hline
\end{tabular}

Table 3. Distribution of personal unhygienic behavior observed ( $\mathbf{N}=\mathbf{1 2 2})$

\begin{tabular}{|c|c|c|}
\hline $\begin{array}{c}\text { OTHER PERSONAL UNHYGIENIC } \\
\text { BEHAVIOR }\end{array}$ & $\mathrm{N}=122$ & $\%$ \\
\hline Shaking hands whilst preparing food & 2 & $1.6 \%$ \\
\hline Chewing whilst preparing food & 1 & $0.8 \%$ \\
\hline Changing money when preparing food & 5 & $4 \%$ \\
\hline
\end{tabular}

protective cloth worn by food handlers

120

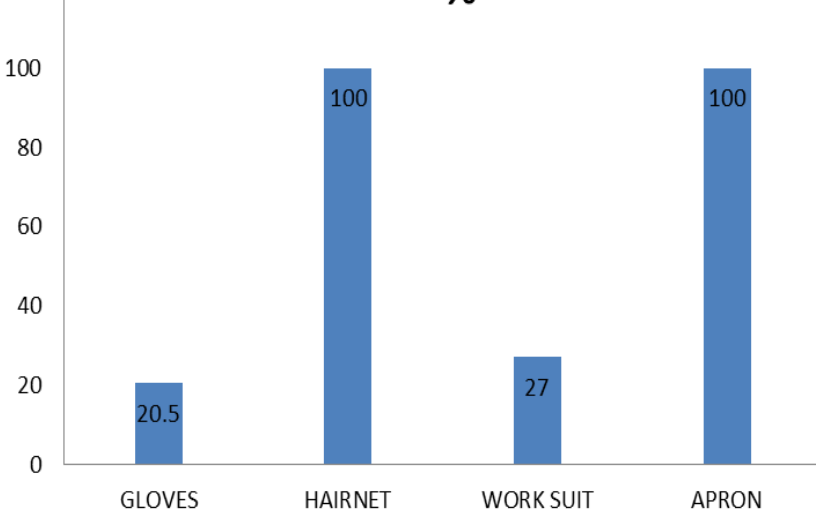

Figure 1. Types of protective wear worn by food handlers

Table 4. Health surveillance practices

\begin{tabular}{|c|c|c|}
\hline HEALTH SURVEILLANCE PRACTICES & $\mathrm{N}=122$ & $\%$ \\
\hline Have medical examination & 44 & 36 \\
\hline Reported illness to management & 108 & 89 \\
\hline Preparing food with cough during visit & 26 & 21.3 \\
\hline Any visible open wounds, injuries at time of visit & 30 & 24.5 \\
\hline
\end{tabular}

Table 5. Hygiene Infrastructure

\begin{tabular}{|l|c|c|}
\hline \multicolumn{2}{|c|}{ Compliance indicator } & \\
\cline { 2 - 3 } & Frequency & $\%$ \\
\hline $\begin{array}{l}\text { 1. Layout, design, construction and size of this } \\
\text { food premises is designed and built to ensure } \\
\text { good hygiene. }\end{array}$ & 55 & 92 \\
\hline $\begin{array}{l}\text { 2. Does the layout protect against the } \\
\text { accumulation of dirt? }\end{array}$ & 55 & 92 \\
\hline $\begin{array}{l}\text { 3. Is there access to potable water at the site or } \\
\text { close to the site? }\end{array}$ & 60 & 100 \\
\hline $\begin{array}{l}\text { 4. Are adequate ventilation facilities which are } \\
\text { also accessible and suitable for cleaning? }\end{array}$ & 59 & 98. \\
\hline $\begin{array}{l}\text { 5. Is the wall free from visible dust, soot, and dirt } \\
\text { or spider web? }\end{array}$ & 55 & 92 \\
\hline $\begin{array}{l}\text { 6. Are ceilings and overhead fixtures designed } \\
\text { and finished to prevent the accumulation of dirt } \\
\text { and contamination of food? }\end{array}$ & 49 & 82 \\
\hline $\begin{array}{l}\text { 7. Do designated wash hand basins have hot and } \\
\text { cold water? }\end{array}$ & 40 & 66 \\
\hline $\begin{array}{l}\text { 8. Do designated wash hand basins have soap / } \\
\text { antibacterial L soap? }\end{array}$ & 60 & 100 \\
\hline $\begin{array}{l}\text { 9. Do designated wash hand basins have hygienic } \\
\text { drying facilities? }\end{array}$ & 50 & 83 \\
\hline $\begin{array}{l}\text { 10. Is environment around the food premises } \\
\text { clean, far from rubbish, waste water, toilet } \\
\text { facilities, open drains and animals? }\end{array}$ & 55 & 92 \\
\hline $\begin{array}{l}\text { 11. Is the toilet clean \&comfortable to use at time } \\
\text { of visit? }\end{array}$ & 56 & 93 \\
\hline
\end{tabular}

\section{Discussion}

\subsection{Personal Hygiene Practices}

According to Section 9(i) (ii) and 11(i) (ii) and (iii) of 
regulation 962 of 2012, promulgated under the Foodstuffs, Cosmetics and Disinfectants Act, No. 54 of 1972 of Republic of South Africa the standard requirements regarding hands are that no person is allowed to handle unpacked food, whose fingernails, hands or clothes are not clean; who has not washed his or her hands thoroughly with soap and water. The current study with regard to personal hygiene practices found varying levels of compliance.

The observation visits showed that $115(94 \%)$ had their finger nails cut. Short and clean fingernails are also important for prevention of transmission of food borne illness. Most of the food handlers had their finger nail cut short as prescribed by regulation 9(i) (ii) of regulations R962 of 2012. The data in this study show a consistency with different literatures which support that there is a high levels compliance, with hand hygiene procedures. This is similar to a study conducted by Assefa et al. (2015) in Ethiopia whereby $80.4 \%$ of food handlers' fingernails were trimmed. Failure by food handlers to adhere to trim and clean nails leads to outbreak of food borne diseases. Studies conducted by Griffith (2000) in the United Kingdom shows that microorganisms are particularly likely to accumulate under long dirty fingernails. This is why fingernails should be cut as short as possible. Therefore contamination can also be transferred to and from food handlers through raw food, hands including dirty fingernails, rings, and other jewellery, clothing, aerosols, fomites, food waste, food packaging and other environmental sources.

In addition food handlers with poor personal hygiene could be the source of food borne pathogens (WHO 1984). The consequence of food contamination varies among countries and regions of the world depending on climate, geography and degree of social and economic development (Shojaei et al., 2006) cited several studies confirming that poor personal hygiene by food handlers has caused outbreaks of food-borne illness caused by various pathogens, including Staphylococcus aureus, gram-negative bacilli Salmonella spp., Shigella spp., Campylobacter jejuni; enter toxigenic Escherichia coli as well as viral agents, Hepatitis A and Norovirus. In a survey of the hands of Iranian food handlers, the most common potentially pathogenic bacteria isolated were Bacillus spp., E. coli, Enterobacter spp., Klebsiella spp. and S. aureus (Shojaei et al., 2006).

In regard to hand washing in this study $(71 \%)$ washed hands with soap. The data in this study show a consistency with different literatures which support that there is compliance, with hand hygiene procedures. This is similar to a study done in a study done in South Africa (2007) (Tonder et al., 2007) found that (94\%) washed their hands under all circumstances. Non washing of hands by food handlers has wide ranging negative public health impacts. Several food-borne disease outbreaks are associated with poor personal hygiene of people handling foodstuffs. Centre for Disease Control (1999) reported that approximately $20 \%$ of food-related infections are due to food handlers.

The hands of ready-to-eat food service employees have been shown to be vectors in the spread of foodborne disease, mainly because of poor personal hygiene. Howes et al. 1999 state that improper food handler practices contributed to approximately $97 \%$ of foodborne illnesses in food service establishments and homes. Statistical evidence indicates that food poisoning caused by the catering industry is $70 \%$ higher than that caused by any other sector (Wilson et al., 1997). Food workers may transmit pathogens to food coming from a contaminated surface of another food, or from hands contaminated with organisms from their gastrointestinal tract. This is also supported by report in which about $89 \%$ of outbreaks caused by food contamination by food workers, pathogens were transferred to food by workers' hands (Michaels et al., 2004).

Food handlers are the most important sources for the transfer of microbial pathogens to food either from their hair, skin, hand, digestive systems, respiratory tracts, or from contaminated food prepared and served by them (Guzevich et al., 1999). The hands are the last line of defence against exposure to pathogens which can occur either directly from the hand to the mouth, eye, nose, or other area of the skin, or indirectly by "handling" of food or water. The hands are particularly important since they are the last line of defence in the chain of transmission of gastrointestinal pathogens, either directly from hand to-mouth, or indirectly by "handling" of food or water (Gun et al., 2007).

In a study conducted by Assefa et al (2015) among Jimma university canteen food handlers the study revealed that $49.6 \%$ participants' hands were contaminated with one or more potentially food borne bacterial contaminants. Staphylococcus aureus $23.5 \%$, Klebsiella species $16.1 \%$, E. coli $0.9 \%$, Enterobacter species $9.1 \%$, Citrobacter species $4.3 \%$, are among the most commonly isolated bacterial hand contaminants. The overall hand contamination rate of enteric bacterial contaminants was $31.7 \%$ among the participants. Toxin-producing strains of Staphylococcus aureus are the leading cause of gastroenteritis following handling of food by persons who carry this bacterium in their noses and skin (Do Carmo 2004).

According to regulation 962 of 2012, promulgated under the Foodstuffs, Cosmetics and Disinfectants Act, No. 54 of 1972 of Republic of South Africa state that no person shall be allowed to handle food without wearing suitable protective clothing. Such clothing should be 1) clean and neat before any food is handled, 2) in a clean condition at all times during the handling of food, 3) of such design and material that it would not contaminate the food, and 4) designed not to come into direct contact with any part of the food. The observation revealed that all the food handlers 122 $(100 \%)$ were observed wearing clean uniforms, make use of aprons or hair nets to cover head when preparing and serving food. The results show that management in fast food outlets provided their food handlers with the required protective clothing as the regulations prescribe. All the food handlers in the fast food outlets use protective clothing prescribed by the health regulations. Section 9 of Regulations R962 of 23 November 2012 prohibits any food handler from handling food without the use of the required protective clothing. This 
study is line with a study conducted among fast food outlets in the delicatessen industry in South Africa in which all food handlers were observed wearing plastic or material apron, gloves and hairnets (Tonder et al., 2007).

All food handlers in fast food outlets have a basic responsibility to maintain a high degree of personal cleanliness and observe hygienic and safe food handling practices; otherwise they can contaminate food sources with pathogenic microorganisms. It is compulsory that food handlers maintain good personal hygiene to ensure food safety in food preparation. During food handling they should remove all jewelry and makeup. It is recommended that people engaged in food processing should avoid any behavior that could result in food contamination. Smoking, spitting, chewing or eating, sneezing or coughing directly over food is unacceptable because it increases the probability of contamination. Personal effects such as jewelry, watches, pins or other such items should not be worn or brought into food handling areas. In this study only $2(1.6 \%)$ of the respondents were observed shaking hands whilst preparing food, whilst $1(0.8 \%)$ were found chewing whilst preparing food and 5(4\%) of respondents were observed collecting money at the same time serving or dishing food. These findings are a concern since the hands are vectors for pathogens such as S.aureus. Consequently, it is advised that food handlers should avoid handling food with bare hands.

\subsection{Health Surveillance Practices.}

According to Government Regulation 962 of 2012, promulgated under the Foodstuffs, Cosmetics and Disinfectants Act, No. 54 of 1972 of Republic of South Africa, medical examination of a food handler should be carried out if clinically or epidemiologically indicated. Conditions which should be reported to management so that any need for medical examination and/or possible exclusion from food handling can be considered, include, jaundice, diarrhea, vomiting, fever, sore throat with fever, visibly infected skin lesions (boils, cuts and discharges from the ear, eye or nose (Codex Alimentarius, 2003).This requirement is supported by guidelines from the South Africa Department of Health, regarding the management and health surveillance of food handlers.

There was $(36 \%)$ compliance in terms of having medical examinations at the time of visiting. Failure by food handlers to undergo medical examination is a threat to the consumers who patronize these fast food outlets. It has been reported in literature that infected food handlers are a threat to the health of the consumers, for example a study conducted in Lagos, South-West, Nigeria reported that the prevalence of Salmonellosis commonly known as typhoid fever among food handlers and the general public in developing country such as Nigeria, and the increasing menace of multi-drug resistance (MDR) by Salmonella spp. is indeed a public health problem. The resultant effect on the health of food consumers would affect productivity, social and other aspect of life. This study showed high incidence of Salmonella infection among food handlers studied (Ogah et al., 2015).

Furthermore it has been shown that the source of most reported foodborne hepatitis A outbreaks has been infected food handlers present at the point of sale such as in a fast food outlet or who prepare food for social events such as a wedding. A single infected food handler can transmit Hepatitis virus to dozens or even hundreds of persons and cause a substantial economic burden to public health (Centre for Disease control 1999). The societal cost of a single foodborne outbreak of hepatitis A in Denver involving 43 cases was estimated to be more than $\$ 800,000$, with $190 \%$ of these costs borne by the public health department and attributed to immunoglobulin administration (Dalton et al., 2004).

The reason for few food handlers with routine medical checkup routine is because of the position of South African Department of Health on medical checkups. According to the department of health South Africa routine medical examinations of food handlers may lead to a false sense of safety which can cause negligence with regard to general hygienic practices and personal hygiene. A much more effective preventative measure, the education of food handlers in hygienic practices, is often also neglected. For these reasons the Department considers pre- employment and routine medical examinations of food handlers as not being cost-effective and unreliable in the prevention of food borne disease and recommends that it should therefore not be required by health authorities. Regular monitoring and surveillance by health authorities and management of the food handling process are, however, crucial elements in the prevention of food borne diseases (Department of Health Guidelines for the management and health surveillance of food handlers 2000).

There was (89\%) compliance in terms of reporting illness to management. This was based on evidence for sick leaves and illness reports which were seen by the researcher. In terms of the regulation food handlers should report illness or sickness to management and managers should encourage employees to report to their supervisors whenever they have diarrhea, sore throat, fever, a cold or open skin lesions, or are jaundiced. Discretion should then be used as to whether or not these persons should be subjected to certain restrictions or suspended from food handling duties. The guidelines issued by the Department of Health in South Africa do not support pre-employment medical examinations but rather the establishment and implementation of procedures to ensure that illness is reported to management. (Department of Health Guidelines for the management and health surveillance of food handlers 2000).

If the food handlers do not adhere to this regulation it will lead to diseases such as intestinal parasitic infections result in malnutrition, morbidity, mortality and socioeconomic impact owing treatment cost and hospitalization. Intestinal parasites, which have direct life cycle, are transmitted by faecal oral route to human through poor personal hygiene. S. typhi is one of the major causes of food and water borne gastroenteritis in human and remains an important health 
problem worldwide. The World Health Organization estimates 16 million new cases and 600,000 deaths of typhoid fever were estimated each year (WHO 2007).

According to Government Regulation 962 of 2012, promulgated under the Foodstuffs, Cosmetics and Disinfectants Act, No. 54 of 1972 of Republic of South Africa Sub regulation 11(ii) it stipulates that food or facility shall not be handled by any ill person people known, or suspected, to be suffering from, or to be a carrier of a disease or illness likely to be transmitted through food, should not be allowed to enter any food handling area if there is a likelihood of their contaminating food. Any person so affected should immediately report illness or symptoms of illness to the management. The Codex Alimentarius, (2003) determines that persons, who are known or suspected of having any disease that might be transmitted by food, are forbidden to handle food items. In this survey there was $21.3 \%$ non-compliance of people who prepared food with cough and $24.5 \%$ non-compliance of food handlers who continued to prepared food with exposed cuts or wounds.

\section{Conclusions}

The study concludes that a significant number of food handlers observed food hygiene and safety practices therefore complied with food hygiene and safety government Regulation 962 of 2012, promulgated under the Foodstuffs, Cosmetics and Disinfectants Act, No. 54 of 1972 of Republic of South Africa. Most of the food handlers observed personal hygiene nails were cut, and wore clean protective clothing and wore hairnets. However of concern some food handlers were observed not washing hands with soap and that they were also observed carrying out unhygienic behaviours such as chewing, shaking hands and exchanging money whilst preparing food.

\section{Recommendations}

In order to improve the hygiene practices of food handlers in fast food outlets it is recommended that:

The municipality should educate the food handlers about food safety regulations through health education and health promotion. Furthermore the municipality should ensure enforcement of compliance by its Environmental Health Practitioners and relevant law enforcement agents. The other recommendation is that the fast food outlets owners should provide protective clothing to food handlers, employ food handlers who are trained in food hygiene and ensuring that they hold regular briefing meetings with food handlers on food hygiene.

\section{REFERENCES}

[1] Aibor, M.S. and Olorunda, J.O. 2006.Environmental Health in the 21 st Century for Professional Students. Lagos. Divine Favour Publishers

[2] Assefa T, Tasew, H, Wondafrash B \& Beker J (2015) Assessment of Bacterial Hand Contamination and Associated Factors among Food Handlers Working in the Student Cafeterias of Jimma University Main Campus, Jimma, South West Ethiopia. Journal of Community Medical Health Education 5, 345.

[3] Brink, H. (2006).Fundamentals of Research Methodology for health Care Professionals ( $2^{\text {nd }}$ ed.).Cape Town: Bevan Group

[4] Burns, N., \& Grove, S. K. (2009). The practice of nursing research: Appraisal, synthesis, and generation of evidence. St. Louis, MO: Saunders Elsevier.

[5] Centers for Disease Control and Prevention. (1999) Prevention of hepatitis A through active or passive immunization: recommendations of the Advisory Committee on Immunization Practices (ACIP). MMWR Recommend Rep; 48(RR-12):1-37.

[6] Codex Alimentarius Commission (2003). Food Standards Programme. Basic text on food hygiene, General Requirements. ( $3^{\text {rd }}$ ed.).Geneva. Codex Alimentarius. Food hygiene: Basic texts. Rome.

[7] Codex Alimentarius. (1997). Recommended International Code of Practice - General Principles of Food Hygiene. Geneva. Codex Alimentarius. Food hygiene: Basic texts. Rome

[8] Dalton CB, Haddix A, Hoffman RE, Mast EE. (1996). The cost of a food safety $\bullet$ CID 2004:38 (1 March) $\cdot 713$ borne outbreak of hepatitis A in Denver, Colo. Archives of Internal Medicine; 156:1013-6.

[9] Department of Health Directorate (2000). Food Control. Guidelines for the Management and Health Surveillance of Food handlers. Pretoria: Government press.

[10] Do Carmo L.S, Cummings, C, Linardi V.R, Dias R.S \& De Souza J.M, (2004) A case study of a massive staphylococcal food poisoning incident. Foodborne Pathogen Dis 1: 241-246.

[11] Green, L, Selman C, Banerjee, A, Marcus R, Medus, C, Angulo FJ, Radke V, \& Buchanan, S. (2005). Food service workers self-reported food preparation practices: An EHS-Net study. International. Journal. Hygiene Environment. Health. 208, 27-35.

[12] Green, L.R., Radke, V., Mason, R., Bushnell, L., Riemann, D.W., Mack, J., Motsinger, M.D., Stigger, T. \& Selman, C. 2006. Factors related to food worker hand hygiene practices. Journal of Food Protec-tion, volume 70(3), pp. 661-666

[13] Griffith, C. 2000, "Food safety in catering establishments", in: Farber, J.M. and Todd, E.C. (Eds.), Safe Handling of Foods, Marcel Dekker, New York, pp. 235-256.

[14] Griffith, J. (2000). Food safety in catering establishments, Safe handling of foods. 235-256). New York: Marcel Dekker

[15] Guilford, J.P. \& Frucher. B; (1973), Fundamental Statistics in Psychology and Education, New York: MC Graw-Hill

[16] Gun, W. \& Satu, S. (2007) Microbial contaminants \& Contamination routes in food industry: 1st open seminar arranged by SAFOODNET in food safety and hygiene networking within new member states and associated 
candidate Countries

[17] Guzevich, J.\& Ross, M ,(1999) Evaluation of risks related to microbiological contamination of ready-to-eat food by food preparation workers and the effectiveness of interventions to minimize those risks.

[18] Hennessy, T.W, Cheng, L, Kassenborg, H, Ahuja, S.D, Mohle-Boetani, J, Marcus R., Shiferaw, B, \& Angulo F.J. (2004). Egg consumption is the principle risk factor for sporadic Salmonella serotype Heidelberg infections: A case-control study in food net sites. Clinical infectious diseases, 38 (3), 237-243.

[19] Howes M, McEwen S, Griffiths M, \& Haris L (1996). Food handler certification by home study: measuring changes in knowledge and behaviour. Dairy Food Environmental Sanitation 3,208-214.

[20] Howes, M, McEwen, S, Griffiths, M, \& Harris, L. Food handler certification by home study: Measuring changes in knowledge and behaviour. Dairy Food Environ San. 1996; 16:737-744.

[21] Michaels B, Keller C, Blevins M \& Paoli G (2004) Prevention of food worker transmission of foodborne pathogens: risk assessment and evaluation of effective hygiene intervention strategies. Food Service Technology.

[22] National Institute for Communicable Diseases: Food borne disease outbreak: Limpopo Province FEBRUARY. 2014. Vol. 13(2). Available at [http://www.nicd.ac.za/]

[23] Ogah, J, Adekunle, O.C \& Adegoke A.A. (2015) Prevalence of Salmonellosis among Food Handlers and the Health Implications on the Food Consumers in Lagos State, Nigeria. Journal of Medical Microbiology \& Diagnosis 2015, 4:2

[24] Polit, D.F \& Beck, C.T. (2006).Nursing research: Generating and Assessing Evidence for Nursing Practice $\left(6^{\text {th }}\right.$
ed.).Philadelphia: Lippincott Williams\& Wilkins.

[25] Republic of South Africa. Regulation 962 of (2012) Regulations governing general hygiene requirements for food premises and the transport of food, promulgated under the Foodstuffs, Cosmetics and Disinfectants Act, No. 54 of 1972. Pretoria: Government Printer; 2012.

[26] Shojaei, H., Shooshtaripoor, J., \& Amiri, M. (2006). Efficacy of simple hand-washing in reduction of microbial hand contamination of Iranian food handlers. Food Research International, 39(5), 525529.

[27] South African Bureau of Standards. (2001). Code of practice: food hygiene management (SABS 049) ( $3^{\text {rd }}$ ed.). Pretoria: Author. SAS/STAT. Cary, NC: SAS Institute, Inc

[28] Tonder I, Lues JFR \& Theron M.M. (2007); The Personal and General Hygiene Practices of Food Handlers in the Delicatessen Sections of Retail Outlets in South Africa. Journal of Environmental Health, 70(4):33-39.

[29] Trochim, W. M. K. (2006). Introduction to Validity. Social Research Methods, retrieved from www.socialresearchmethods.net/kb/introval.php, September 9, 2015.

[30] WHO, 1984. The Role of Food Safety in Health and Development. World Health Organization Technical Report Series No 705. Geneva.

[31] Wilson M, Murray AE, Black M.A. \& McDowell, D.A. (1997). The implementation of Hazard Analysis and critical control points in hospital catering. Managing Service Quality; 7(3): 150-156

[32] World Health Organization. 2007. World Health Statistics. Google Internet, October.

[33] World Health Organization. 2007. World Health Statistics. Google Internet, October. http://www.who.int/] 